\title{
What Is Affecting the Residents' Subjective Perception toward Objective Environment Quality?
}

\author{
Jihong Zhang, ${ }^{1}$ Chaopeng Xie ${ }^{1},{ }^{1}$ Chuan Chen $\left(\mathbb{D},{ }^{2}\right.$ Ninghan $X u,{ }^{1}$ and Rui Gao ${ }^{1}$ \\ ${ }^{1}$ Institute of Quality Development Strategy, Wuhan University, Wuhan, China \\ ${ }^{2}$ Department of Service Science and Operations Management, School of Management, Zhejiang University, Hangzhou, China
}

Correspondence should be addressed to Chuan Chen; chuanchen@zju.edu.cn

Received 2 March 2021; Revised 28 May 2021; Accepted 11 July 2021; Published 31 July 2021

Academic Editor: Wei Zhang

Copyright ( 2021 Jihong Zhang et al. This is an open access article distributed under the Creative Commons Attribution License, which permits unrestricted use, distribution, and reproduction in any medium, provided the original work is properly cited.

Environmental quality assessment is an important way to promote the improvement of urban environmental quality. Environmental performance is usually used to evaluate the improvement of environmental quality, and residents' satisfaction with environmental quality is also an important method to evaluate environmental improvement. At present, in many cities in China, the results of the two evaluation methods vary greatly. Residents' environmental satisfaction is not high in some cities with good environmental performance; however, in cities with poor environmental performance, residents' environmental satisfaction is higher. Here, based on the environmental subjective assessment of more than 4,600 independent samples from 56 cities in 2014, this paper constructed an index between subjective and objective scores for each sample and its city, separating the total samples into two groups. In order to analyze the differences between groups, firstly, the important factors driving the differences were extracted by random forest. Secondly, the key individual characteristics were identified by the model based on conditional inference tree. Finally, the regional heterogeneity was analyzed by nonmetric multidimensional scaling. The results show that population density is the main factor that affects the difference between subjective and objective evaluations. Furthermore, in those cities with low population density, investment increasing in transportation infrastructure helps to improve urban air quality, which can bring about more perceptual environmental optimization to people. As individuals, education is the key factor for residents when it comes to environment evaluation, but it is not a simple linear relationship. In terms of regional heterogeneity, the consistency of important factors among regions is not obvious, and the situation that "neighboring" cities share the same factors is not significant.

\section{Introduction}

1.1. Background. As the gathering place of industrial, commercial, and traffic pollution sources, cities have also become the main carrier of improving environmental quality. The pollutants produced by urban production and living account for $80-90 \%$ of the global pollutant production. As the basic administrative unit in China, the city's strategy of implementing environmental governance directly determines the level of urban environmental quality, and environmental quality evaluation is an important way to promote the improvement of urban environmental quality $[1,2]$. To improve the quality of the environment, the Chinese government has issued new policies on the basis of existing environmental policies and regulations.

In 2013, the Air Pollution Prevention and Control Action Plan was released; the ministry of environmental protection and 31 provinces (autonomous regions and municipalities directly under the central government) signed the Target Responsibility Statement for the prevention and control of air pollution in 2014. Meanwhile, the Water Pollution Prevention and Control Action Plan was performed, and the newly revised Law of Environmental Protection came into effect. Releasing the soil pollution prevention and control plan and the law of environmental protection tax in 2016 and starting the environmental protection "Over Check" together with the law of 
environmental protection tax came into effect, making the environmental regulation further strengthened. However, there are still two contrasts of environmental quality: one contrast exists between pollutant emission reduction and environmental quality and the other exists between environmental performance and public perception of the environment [3].

According to the state of "the environment bulletin of China" (2013-2018) issued by the Ministry of Ecology and Environmental Protection, the average annual PM2.5 concentration has dropped from $72 \mu \mathrm{g} / \mathrm{m} 3$ to $47 \mu \mathrm{g} / \mathrm{m} 3$, the annual concentration of PM10 decreased from $118 \mu \mathrm{g} / \mathrm{m} 3$ to $81 \mu \mathrm{g} / \mathrm{m} 3$, the annual concentration of $\mathrm{SO}_{2}$ reduced from $40 \mu \mathrm{g} / \mathrm{m} 3$ to $15 \mu \mathrm{g} / \mathrm{m} 3$, annual concentration of $\mathrm{NO}_{2}$ dropped from $44 \mu \mathrm{g} / \mathrm{m} 3$ to $36 \mu \mathrm{g} / \mathrm{m} 3$, and CO annual average concentration decreased from $2.5 \mu \mathrm{g} / \mathrm{m} 3$ to $1.6 \mu \mathrm{g} / \mathrm{m} 3$ over the past five years. The annual concentration of $\mathrm{O}_{3}$ increased from $139 \mu \mathrm{g} / \mathrm{m} 3$ to $169 \mu \mathrm{g} / \mathrm{m} 3$, chemical oxygen demand (COD) emissions decreased by $14.06 \%$, and ammonia nitrogen emissions decreased by $43.22 \%$ (Statistical Yearbook of the Republic of China 2018). These data fully demonstrate that China's environmental protection work has achieved remarkable results. According to the official statistics of the effect of policy implementation, compared with 2015, the proportion of surface water with a quality of III or better increased by 8.9 percentage points, reaching $74.9 \%$ in 2019 . The proportion of inferior surface water decreased by 6.3 percentage points to $3.4 \%$. The concentration of PM2.5 in cities at or above the prefectural level that failed to meet the standards fell by 23.1 percent.

However, the public perception and media attention are in stark contrast. According to the "Environmental Quality Special Online Survey" organized by the "WOYAO Online Survey," more than $83 \%$ of the respondents believe that "the environmental pollution" situation around them is relatively serious or very serious. Before that, the OECD commissioned Gallup has surveyed 158 countries from 2006 to 2008, the relevance between pollutant emission level and environmental satisfaction was studied, especially during the happiness survey. It is proved that there is a strong positive correlation between pollutant emission reduction and environmental quality satisfaction, based on the level of country and city. The correlation coefficient is $r=0.61$ [4].

Why is there such a big contrast between the environmental quality assessment based on public perception and the environmental quality assessment based on pollutant emission level in China? It has been modified in the article; other possible errors have been checked and corrected. What is the reason for this contrast?

In order to explain the reason for the contrast, this paper makes a comparative analysis of the regional pollutant emission level and the public environmental quality satisfaction using the data from a large-scale environmental satisfaction survey conducted at the city level in China through "WOYAO Online Survey" in August 2016. By carrying out comparative analysis of regional pollutant discharge levels and public environmental quality satisfaction, this paper tries to find out the regularity of contrast between the two and find the lack of environmental protection work. As a result, we can enrich theories and methods of environmental quality assessment and provide some references for China's environmental protection work and ecological civilization construction; it can also answer the above questions.

1.2. Definition of Environmental Quality. A large number of studies have characterized the environmental quality by the emission level of a certain pollutant or the comprehensive index of the emission level of various pollutants, such as sulfur dioxide, nitrogen dioxide, and sewage volume or PM10, PM2.5, and so forth. However, the Dictionary of World Economy and the Dictionary of Capitalism point out that environmental quality is an essential attribute of environmental system, represents the degree to which the overall or certain elements of the environment in a specific time or space satisfy human survival, reproduction, and socioeconomic development, and is a concept of environmental assessment that reflects the specific requirements of the population.

The study in [5] pointed out that "high environmental quality represents residents' high satisfaction and happiness towards the objective physical or social environment." The study in [6] argued that not only is environmental quality limited to pollutant emission level, but also it is a complicated issue involving subjective feelings, attitudes, and values that vary from a person to another. In 2002, an international academic conference on "livability" held in Bouwman reached a consensus about environmental quality. It defines environmental quality as an important component of quality of life, whose essence is residents' comfort of living environment [7]. ISO (the International Standardization Organization, 2000) comprehensively defines "quality" as "the degree to which an inherent set of features meets requirements." From the perspective of public goods, if "environment" is regarded as a public product, environmental quality can be understood as the objective level of a region's environment (i.e., the level of pollutant control) to meet the environmental needs of residents. Therefore, in combination with the original definition of "quality" as "the degree to which a set of inherent characteristics meet the needs" (ISO, 2000), "environment" is regarded as a public product, and "environmental quality" can be understood as the degree to which the objective level of an area's environment (the level of pollutant control) meets the environmental needs of residents.

\subsection{Evaluation Methods of Environmental Quality.} Environmental quality assessment activities began in the mid-1960s, and the United States was the first country to start environmental quality assessment. They had introduced, for example, the Green Composite Air Pollution Index and the Oak Ridge Air Quality Index for the first time. At that period, a single pollutant is mainly used to characterize the environmental quality and sulfur dioxide, nitrogen oxide, nitrogen dioxide, industrial waste gas, industrial smoke, and industrial waste water which are commonly used as indicators to measure the environmental 
quality. Subsequently, environmental quality assessment and theoretical research have been carried out in various countries. Among them, Japan takes environmental quality assessment as an important policy to implement. The reason is that a single index is too general or cannot fully reflect the overall picture of environmental quality in a region, and subsequent studies have integrated a variety of environmental pollutant emission indicators into a comprehensive index through different methods. For example, Rolf Fare and others constructed the environmental performance index with the list of toxic substances. With the development, more environmental indicators are included, such as PM10, PM2.5, $\mathrm{CO}_{2}$, and greenhouse gases. There are also scholars who conduct environmental quality satisfaction surveys based on residents' perceptions and carry out environmental quality evaluation. As an important evaluation content of sustainable development, environmental quality evaluation is also evaluated from the relationship between environment, society, and economy. Many environmental quality evaluation indexes and methods are proposed from different perspectives and methods.

\subsection{Literature on Subjective and Objective Evaluation of} Environment. Until now, most studies on social indicators have focused on a single objective or subjective measurement. Although one indicator can help explain the other, relatively few empirical attempts have been made to combine the two methods in a single study. One of the important reasons is that the inclusion of subjective evaluation is a problem to be considered carefully, due to its value judgment property. It tends to become the focus of the debate rather than an effective way to measure pollution. Many of these factors, including personal and social characteristics such as age, income, education, and health status can act as "filters" that distort objective conditions by intervening between the objective world and an individual's assessment of the objective world. Thus, individual perception transforms what was initially seen as a universal objective condition into a highly individualistic interpretation of this objective condition. However, any definition of the quality of the living environment must include two basic elements: one is the internal psychophysiological mechanism that produces satisfaction and the other is the two dimensions of external phenomena associated with it. Meanwhile, both dimensions of environmental assessment strive to be objective because they strive to have effective, reliable, sensible, and useful repeatable measures [8]. Moreover, both are subjective because even technical assessments depend on human decisions about the dimensions to examine, the time and place of sampling, and the interpretation of the results. Many literatures have begun to draw meaningful conclusions through subjective and objective environmental assessments and many previous studies on environmental perception have been based on interviews with tourists, where issues such as recreational use, tourism infrastructure, and safety may interfere with the perception of major environmental factors [9]. This is also true of interviews with residents, where environmental perceptions may be strongly influenced by the culture in the landscape environment [10], local social and economic conditions (Xu et al., 2006), and information from the media [11].

Generally speaking, "environmental quality" has both subjective and objective attributes. Subjectivity refers to residents' perception of the environment, which can be represented by environmental satisfaction. For the convenience of expression, the measurement of environmental quality based on the emission level of environmental pollutants will be represented by the objective evaluation of environmental quality, while the measurement of satisfaction of environmental quality based on the subjective feelings of residents will be represented by the subjective evaluation of environmental quality in the following paper.

\section{Data and Methods}

2.1. Data Source. This paper adopts the Gallup survey method and covers 56 cities in 26 provinces (municipalities directly under the central government) in China, excluding Hong Kong, Macao, Taiwan, and other regions. The 56 cities include 24 provincial capitals and some prefecture-level cities in each province. The selection of other prefecturelevel cities is mainly based on the stratified sampling method of per capital GDP ranking. The specific sampling method is as follows: If the population of the province is less than 50 million, the cities with the median ranking are selected. If the population of the province is more than 50 million, more than two cities will be selected in addition to the provincial capital cities, ranking the cities at $40 \%$ and $70 \%$, respectively. In the surveyed cities, samples were taken according to different income levels, and 30-50 samples were selected according to different populations. As a result, 4660 valid samples were obtained. Among the 4660 samples, nonagricultural registered residents accounted for $70.05 \%$, while agricultural registered residents accounted for $29.05 \%$, with $49.85 \%$ men and $50.15 \%$ women. In terms of education level, high school and below accounts for $27.22 \%$, college, technical secondary school, and vocational high school account for $27.88 \%$, and bachelor's degree and above accounts for $44.90 \%$. The survey on environmental quality in the questionnaire includes five aspects: residents' perception and satisfaction with the overall environment, air quality, water quality, noise, and vegetation. Moreover, "1" means very dissatisfied, " 6 " means very qualified, and 10 means very satisfied. The subjective perception data of environmental quality in this paper are formed, and the overall evaluation results are shown in Figure 1.

2.2. Objective Evaluation. As mentioned in Table 1, in the process of evaluating the overall quality of the environment, single-dimensional indicators will produce the problem of overgeneralization, while multidimensional indicators lack a unified composition standard, resulting in different composition of comprehensive indicators and inconsistent evaluation results, which is not conducive to comparison. Also, the indexes are numerous, and the calculation is complex due to the shortage of result continuity. In this 


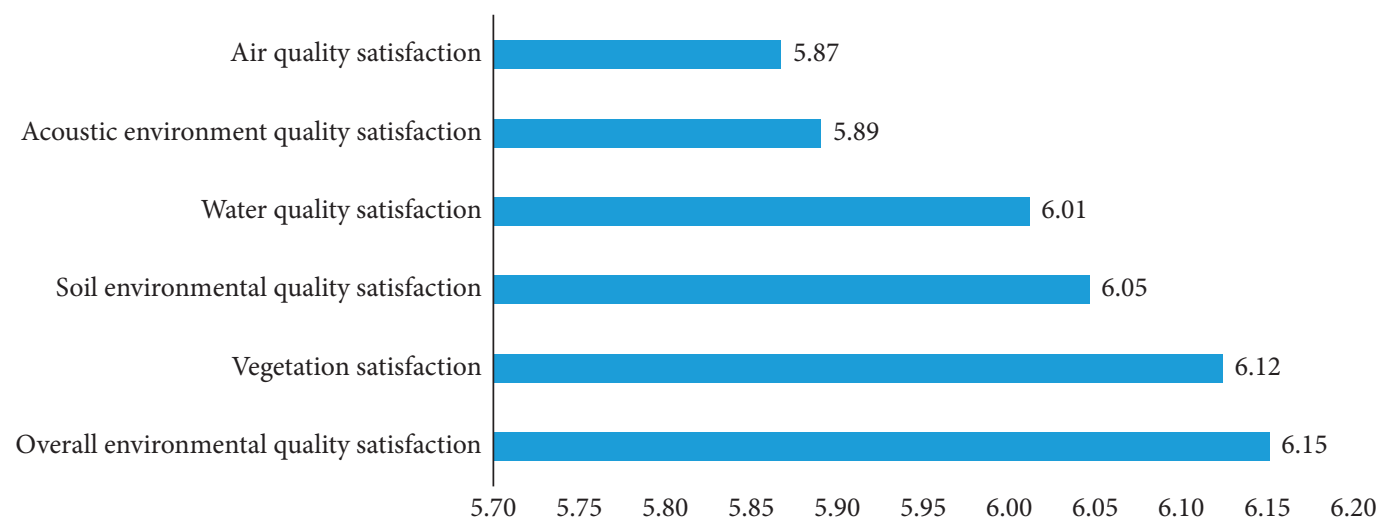

FIGURE 1: Environmental quality satisfaction score.

paper, since the objective evaluation system needs to be compared with the evaluation results of the supervisor, the environmental changes that are more easily perceived by residents in real life are mainly due to the pollution or purification level of water, gas, and solid. Hence, in order to make the results more comparable, this paper chooses three types of pollutants that are more easily perceived and pollution treatment level to construct system indicators. Based on the multidimensional analysis system, the weighted average method is used to calculate the objective evaluation index of environmental quality. The rating system is given in Table 2.

The pollutant emission data of each city mainly came from China Statistical Yearbook 2012-2015, China Environmental Statistical Yearbook 2012-2015, and China Urban Statistical Yearbook 2012-2015. In those three statistical yearbooks, air quality indicators include total $\mathrm{SO}_{2}$ emissions, total $\mathrm{NO}_{2}$ emissions, and PM10. Indicators of water environmental quality include total discharge of waste water and concentrated treatment rate of waste water. Meanwhile, the pollution treatment uses the solid waste treatment rate and the garbage disposal rate.

2.3. Random Forest. Random forest is a combination of tree classifiers, where each classifier is generated by using a random vector sampled independently from the input vector, and each tree casts a unit vote for the most popular class to classify an input vector. The method, which adds an additional layer of randomness to bagging [12], changes the algorithm utilizing averaging multiple deep decision trees and trains on different parts of the same training set with the goal of reducing the variance against overfitting. Besides, it is very user-friendly in the sense that it has only two parameters (the number of variables in the random subset at each node and the number of trees in the forest), and it is usually not very sensitive to their values. In the same manner as the decision tree, the random forest classifier uses the Gini index as an attribute selection measure to assess the impurity of an attribute concerning the classes. However, relationships between variables assessed by stochastic forest models are treated as a "black box" that requires advanced mathematical knowledge to explain.
The mechanism of random forest is beyond the scope of this study. In this paper, we mainly use the importance of random forest as the ranking of the importance of driving factors. Here are the definitions of the variable importance measures. The first measure is computed from permuting OOB data: For each tree, the prediction error on the out-ofbag portion of the data is recorded (error rate for classification and MSE for regression). Then the same is done after permuting each predictor variable. The differences between the two are then averaged over all trees and normalized by the standard deviation of the differences. If the standard deviation of the differences is equal to 0 for a variable, the division is not done (but the average is almost always equal to 0 in that case). The second measure is the total decrease in node impurities from splitting on the variable, averaged over all trees. For classification, the node impurity is measured by the Gini index. This method has been applied to study the relationship among climate change, energy consumption, and people's subjective perceptions or attributes [13].

2.4. Conditional Inference Tree (CTREE). The model of a conditional inference tree is another type of machine learning algorithm that can be used as a classifier and a regression. The "tree" refers to a hierarchical model of decisions and its results. The application of decision tree method in environmental assessment is still rare. Compared with random forest, the tree-based model has relatively clear, simple, and easy-to-understand rules. Because it does not need to optimize the geometry and internal network, it can be programmed faster than a random forest model. Furthermore, because most recursive partitioning algorithms are special cases of simple two-phase algorithms, the observations of a univariate partition are first partitioned recursively, and then a constant model is installed in each cell of the result partition. The most popular implementations of this algorithm are "CART" [14] and "C4.5" [15]. Similar to AID, both perform exhaustive searches for all possible segmentations to maximize the information measure of node impurities and select the covariates that display the best segmentation. However, there is a basic problem with this approach: there is no concept of statistical significance, so it is impossible to distinguish the significance and 
TABLE 1: Comparison of environmental quality assessment methods.

\begin{tabular}{|c|c|c|c|c|}
\hline $\begin{array}{l}\text { Evaluative } \\
\text { dimension }\end{array}$ & Name of index & Explanation & Advantage & Disadvantage \\
\hline $\begin{array}{l}\text { Unidimensional } \\
\text { index }\end{array}$ & $\begin{array}{l}\text { Waste indicator } \\
\text { Forest environmental } \\
\text { indicators }\end{array}$ & $\begin{array}{l}\text { A unit of environmental } \\
\text { pollutant such as sulfur } \\
\text { dioxide, suspended matter } \\
\text { concentration (SPM), } \\
\text { carbon monoxide, carbon } \\
\text { dioxide, and nitrogen } \\
\text { oxides. } \\
\text { One kind of water pollutant } \\
\text { is taken as the content of } \\
\text { environmental assessment, } \\
\text { such as industrial } \\
\text { wastewater and chemical } \\
\text { oxygen demand (COD). } \\
\text { Hazardous waste is taken as } \\
\text { the index of environmental } \\
\text { evaluation, such as solid } \\
\text { waste and liquid waste. } \\
\text { Forest coverage rate is the } \\
\text { main index of } \\
\text { environmental quality } \\
\text { evaluation. } \\
\text { The utilization efficiency of } \\
\text { a certain natural resource is } \\
\text { taken as the index of } \\
\text { environmental } \\
\text { comprehensive evaluation. }\end{array}$ & $\begin{array}{l}\text { Single-dimensional indicators } \\
\text { are straightforward and easy } \\
\text { to understand, data } \\
\text { availability is strong, } \\
\text { continuity is strong, it is easy } \\
\text { to compare and study, and } \\
\text { local environmental problems } \\
\text { are targeted. }\end{array}$ & $\begin{array}{l}\text { In the process of evaluating the } \\
\text { overall quality of the } \\
\text { environment, there will be an } \\
\text { overgeneralization problem. }\end{array}$ \\
\hline $\begin{array}{l}\text { Multidimensional } \\
\text { index }\end{array}$ & $\begin{array}{l}\text { Comprehensive } \\
\text { indicators for the } \\
\text { discharge of various } \\
\text { pollutants }\end{array}$ & $\begin{array}{l}\text { A variety of environmental } \\
\text { factors are integrated into a } \\
\text { comprehensive indicator of } \\
\text { environmental quality, such } \\
\text { as industrial emissions, } \\
\text { industrial waste water } \\
\text { emissions, and industrial } \\
\text { solid emissions. } \\
\text { Environmental quality is an } \\
\text { important part of } \\
\text { sustainable development. } \\
\text { The relationships between } \\
\text { environment and society, } \\
\text { between environment and } \\
\text { economy, between } \\
\text { environment and ecology, } \\
\text { and between environment } \\
\text { and human development } \\
\text { are evaluated. } \\
\text { Taking residents' perceived } \\
\text { environmental quality } \\
\text { satisfaction as the } \\
\text { evaluation index, the } \\
\text { satisfaction data were } \\
\text { obtained by means of } \\
\text { questionnaire survey, } \\
\text { including air quality } \\
\text { satisfaction, water quality } \\
\text { satisfaction, vegetation } \\
\text { satisfaction, and acoustic } \\
\text { environment satisfaction. }\end{array}$ & $\begin{array}{l}\text { The multidimensional } \\
\text { environmental quality } \\
\text { evaluation index can reflect } \\
\text { the overall situation of } \\
\text { environmental quality in a } \\
\text { comprehensive way, which is } \\
\text { conducive to an objective, fair, } \\
\text { and reasonable } \\
\text { comprehensive evaluation of } \\
\text { environmental quality. It can } \\
\text { also reflect the ability of } \\
\text { sustainable development from } \\
\text { the environmental dimension. }\end{array}$ & $\begin{array}{l}\text { Due to the lack of unified } \\
\text { criteria for the composition of } \\
\text { multidimensional evaluation } \\
\text { indicators, the composition of } \\
\text { comprehensive indicators is } \\
\text { different, and the evaluation } \\
\text { results are inconsistent, which } \\
\text { is not conducive to } \\
\text { comparison. Because the } \\
\text { indexes are numerous, the } \\
\text { calculation is complex, causes } \\
\text { the result continuity to be not } \\
\text { good, and is disadvantageous } \\
\text { to discover the historical } \\
\text { regularity. }\end{array}$ \\
\hline
\end{tabular}


TABLE 2: Objective evaluation system of environmental quality.

\begin{tabular}{|c|c|}
\hline The first layer & The second layer \\
\hline Air quality (35\%) & $\begin{array}{c}\mathrm{SO}_{2}(33.3 \%) \\
\mathrm{NO}_{2}(33.3 \%) \\
\mathrm{PM} 10(33.3 \%)\end{array}$ \\
\hline Water quality (30\%) & $\begin{array}{c}\text { Total discharge of wastewater }(50 \%) \\
\text { Concentration rate of sewage treatment }(50 \%)\end{array}$ \\
\hline Pollution treatment (35\%) & $\begin{array}{c}\text { Solid waste disposal rate }(50 \%) \\
\text { Centralized rate of garbage disposal (50\%) }\end{array}$ \\
\hline
\end{tabular}

insignificance of information measures. The conditional inference tree provides an integrated framework for embedding recursive binary division into the well-defined permutation test theory proposed by [16]. By doing so, multiple testing procedures are applied to determine whether any covariables and responses can be declared without a significant correlation, and the recursion is stopped when it is needed.

2.5. Nonmetric Multidimensional Scaling (NMDS). The nonmetric multidimensional scaling is a data analysis method that simplifies the research objects (samples or variables) of multidimensional space to lower-dimensional space for positioning, analysis, and classification, while retaining the original relationship between these objects [17]. It is applicable to the case where the exact similarity or heterogeneity data between the objects cannot be obtained, and only the hierarchical relationship data among them can be obtained. Its basic characteristic is to regard the similarity between objects or the data of phase as the monotone function of the distance among the points and replace the original data with new data columns of the same order on the basis of maintaining the order relation of the original data for metric multidimensional scaling analysis [18]. Put differently, when the data is not suitable for the analysis of variable-type multidimensional scale directly, the variable transformation is carried out, and then the variable-type multidimensional scale analysis is adopted. For the original data, it is called the nonmetric multidimensional scale analysis. Its characteristic is that, according to the species information contained in the samples, it is reflected in the multidimensional space in the form of points. Furthermore, the degree of difference between different samples is reflected by the distance among the points, and finally the spatial location map of samples is obtained.

\section{Results}

3.1. Evaluation Index and Ranking of Urban Environmental Quality. Based on the subjective and objective evaluation methods selected in the previous article, we calculated the subjective and objective environmental evaluation scores and rankings of each city, as shown in Figure 2. In Figure 2(a), the length of the blue column represents the objective ranking order, and orange represents the subjective ranking order. The column length in Figure 2(b) indicates the difference between the subjective ranking and objective ranking. The larger the value is, the lower the subjective ranking is compared with the objective ranking. In many cities, subjective and objective evaluations differ greatly, which is also consistent with the results of previous studies.

In order to measure the difference value of each sample, we subtracted the standardized objective score of the city where each sample was located from the standardized subjective score of each sample and constructed a new difference index heter in the following analysis. The samples were divided into groups greater than 0 and less than 0 by this index. Figure 3 shows the kernel density function graph of heter.

3.2. Extracting the Main Driving Factors. Based on the grouping of difference index, we add all characteristic factors of all samples into the model and extract the most important driving factors through random forest. In Figure 4, the importance of all relevant variables is ranked. The larger the value is, the more important the variable is. It can be found that population density is the most important factor by two different measures. Therefore, we can assume that population density has the greatest influence on urban environmental evaluation [19]. Since the two measures are only important references, the first four factors are selected from the two groups of species, and a total of eight factors (including coincidence) are selected as the most important elements which will be used as the basis for further CTREE analysis.

Further factor extraction was conducted for each city through random forest; we found that the occurrence frequency of education factor was the highest among the top three factors from a national perspective. In the 55 cities (due to missing data), 28 (51\%) had educational factors in the top three influencing factors (see chart in dark red in Figures 5 and 6). Figures 5-7 show the distribution of the top three influencing factors in each province (Figure 7 shows the third most important factor). As mentioned in the previous article, the education factor has become the most frequent factor in many provinces. Among numerous studies on education and environmental quality, more and more scholars have found that there is no obvious direct relationship between education and mortality caused by air pollution $[20,21]$, and education interacts with other socioeconomic environments in complex ways in terms of influencing people's health and quality of life. Therefore, we can assume that there is not a general and monotonous relationship between the advantages and disadvantages of 


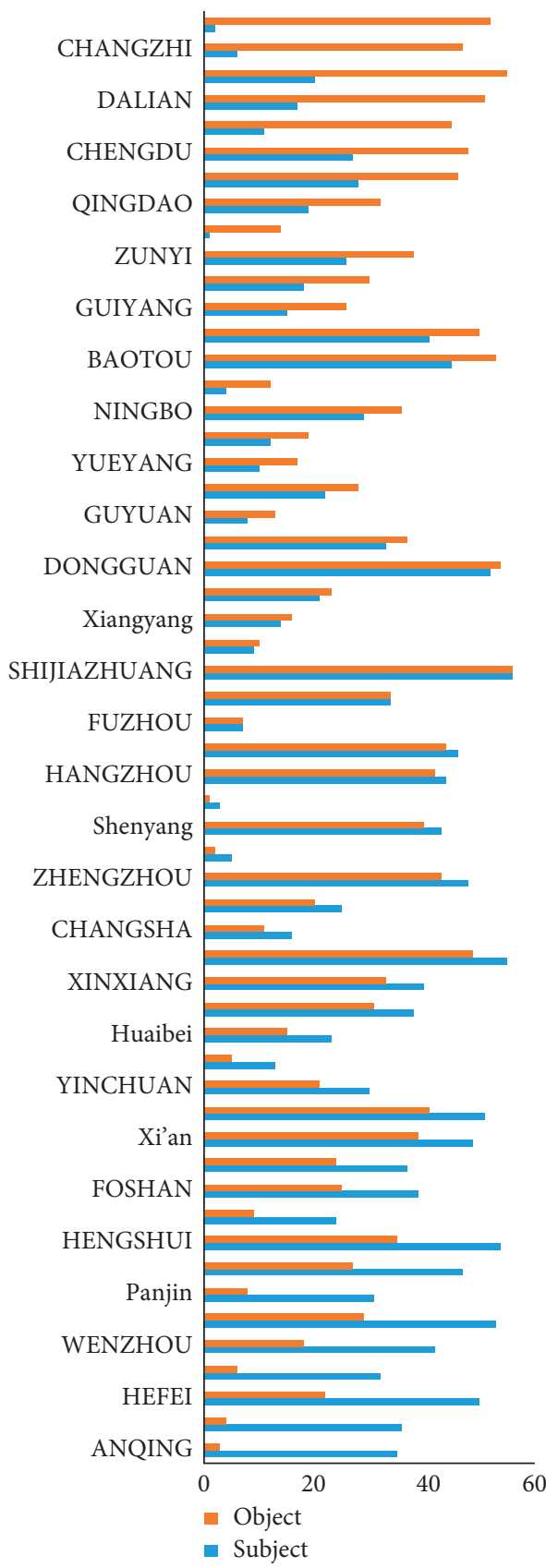

(a)

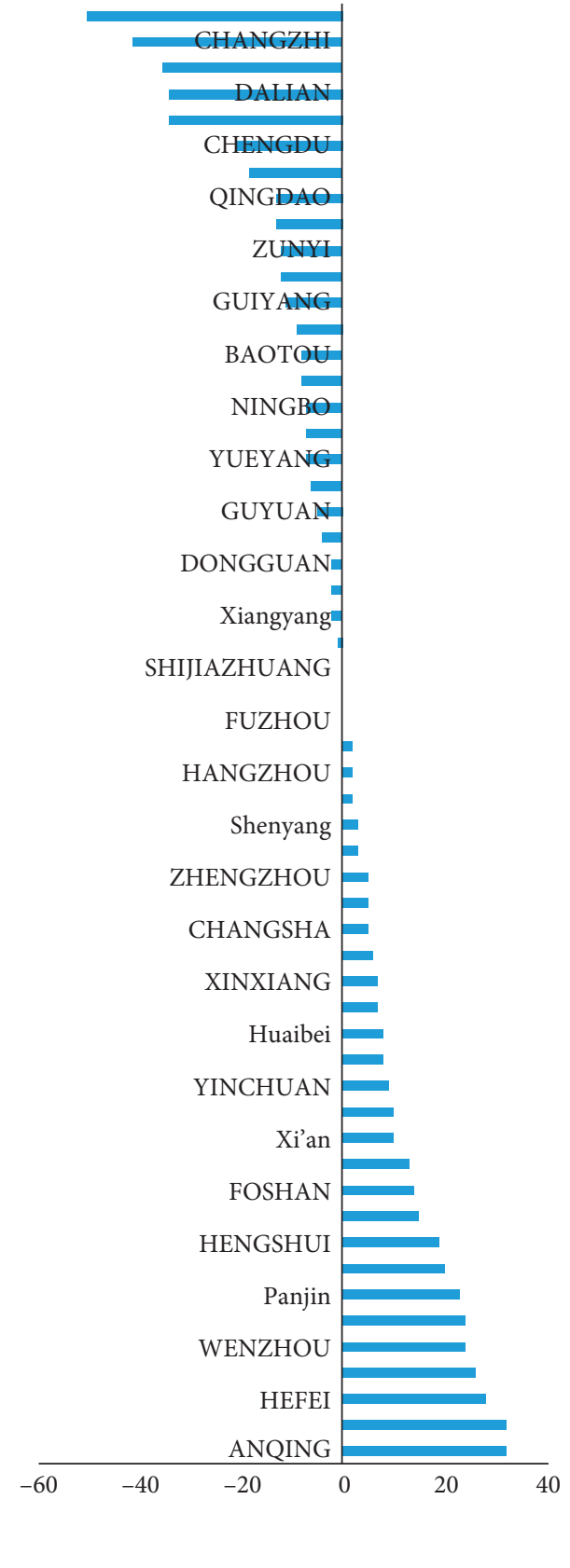

(b)

Figure 2: The subjective ranking and objective ranking and difference of environmental quality in each city.

urban evaluation among people with different educational levels. We will prove this by the conditional inference tree in the following passage.

3.3. Feature Classification Analysis. Based on the important driving factors of random forest extraction, we obtain the integral sample $(N=4652)$ of conditional inference tree. A stacked bar chart for each terminal node shows the percentage of individuals whose subjective evaluation is higher than the objective "1" (in black) or whose subjective evaluation is lower than the objective "0" (in light). Each tree has three layers. We set a $95 \%$ confidence interval as one of the conditions that the number of branches can be used as a node, so that each node reports the corresponding $P$ value.

The most important variable in Figure 8 is population density, which is consistent with the screening results of random forest. Secondly, for the urban road area, we found that, in the group with moderate population density, node 11 completely divided the urban road area into two groups: "high, low" and "medium," while the group with high subjective evaluation accounting for the largest proportion was "medium." Then observe node 2 and node 5 and ignore the influence of education node 7 . In the group of low 


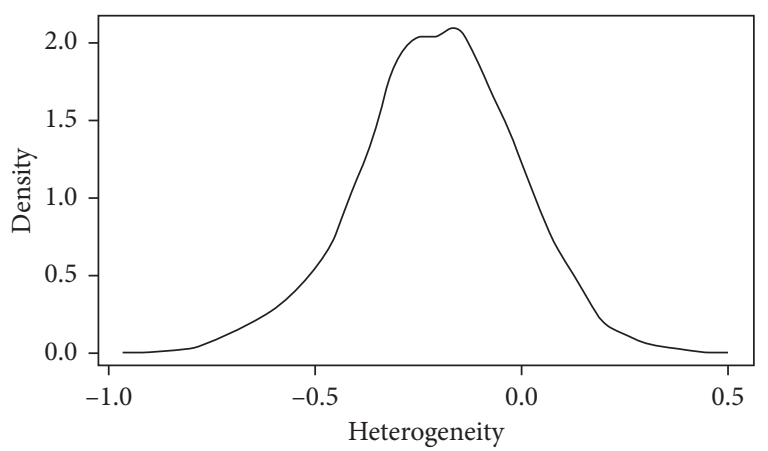

FIGURE 3: Differential exponential kernel density function diagram.
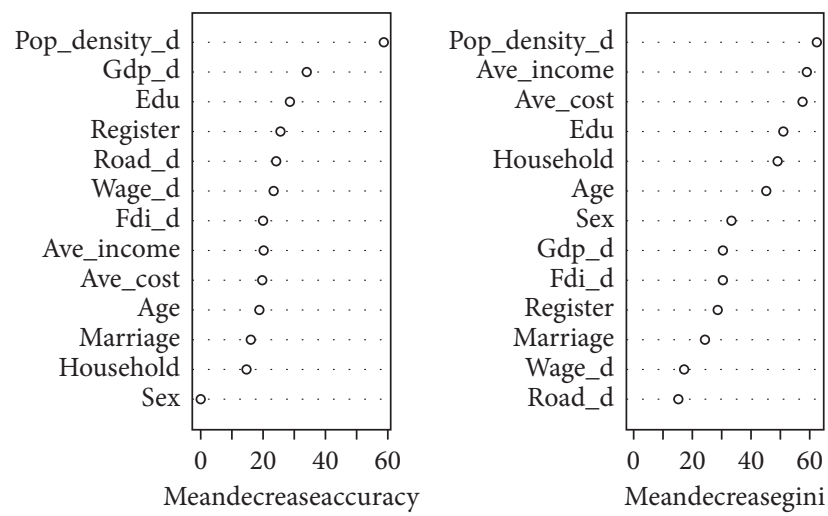

FIGURE 4: Factors in order of importance.

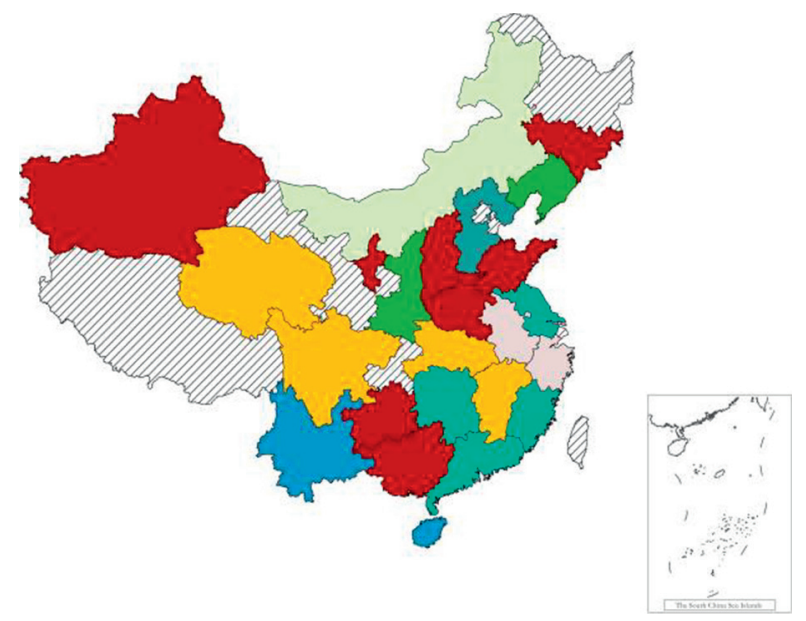

TOP1

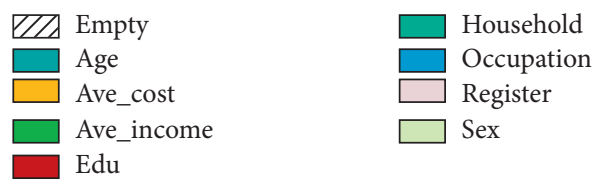

FIGURE 5: The top one factor in each province.

population density and high urban road area (node 6), the percentage of people with higher subjective evaluation is significantly higher than that of other groups. The former shows that extreme population density and urban road area may not bring better subjective evaluation of environmental

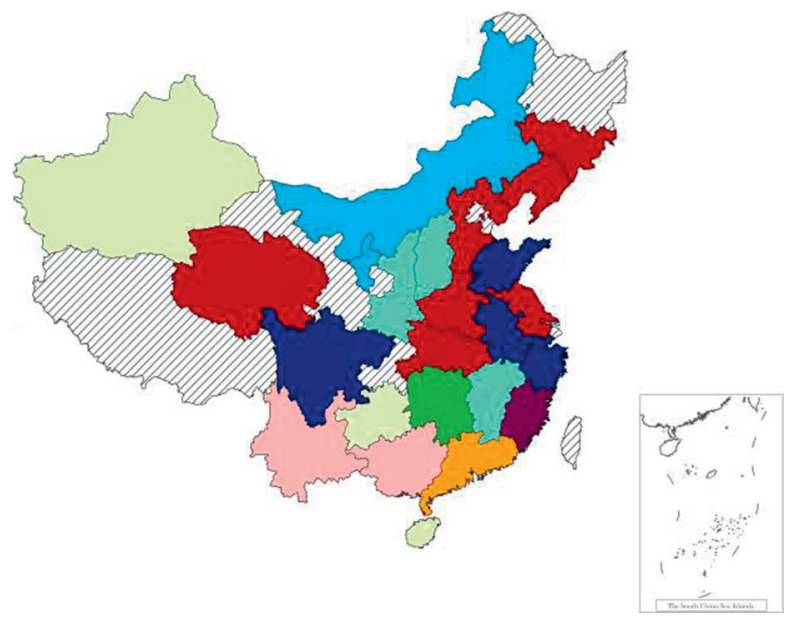

TOP2

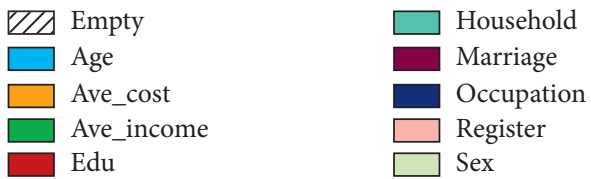

FIgURE 6: The second factor in each province.
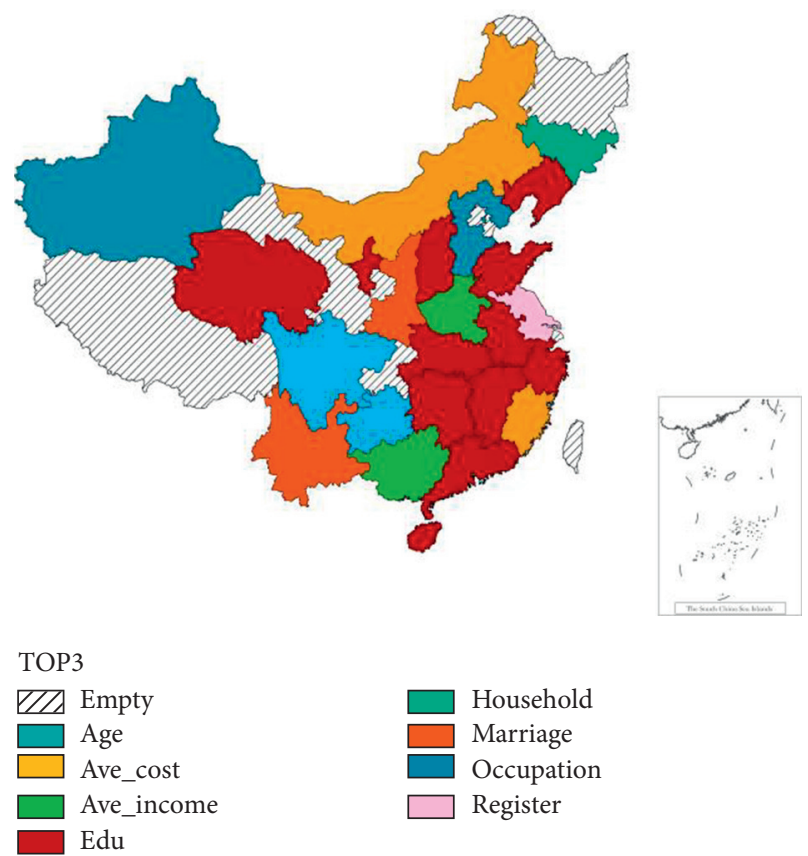

Figure 7: The third factor in each province.

quality. The latter indicates that, in the case of lower population density, if the city has a larger urban road area, the probability of obtaining higher subjective evaluation is significantly higher than that of the group with lower road area. Hence, on the basis of previous researchers [22], we can draw the conclusion that, in cities with low population density, increased investment in transportation infrastructure can improve urban air quality, because it can bring people more perceived environmental optimization, which is also very consistent with our hypothesis. 


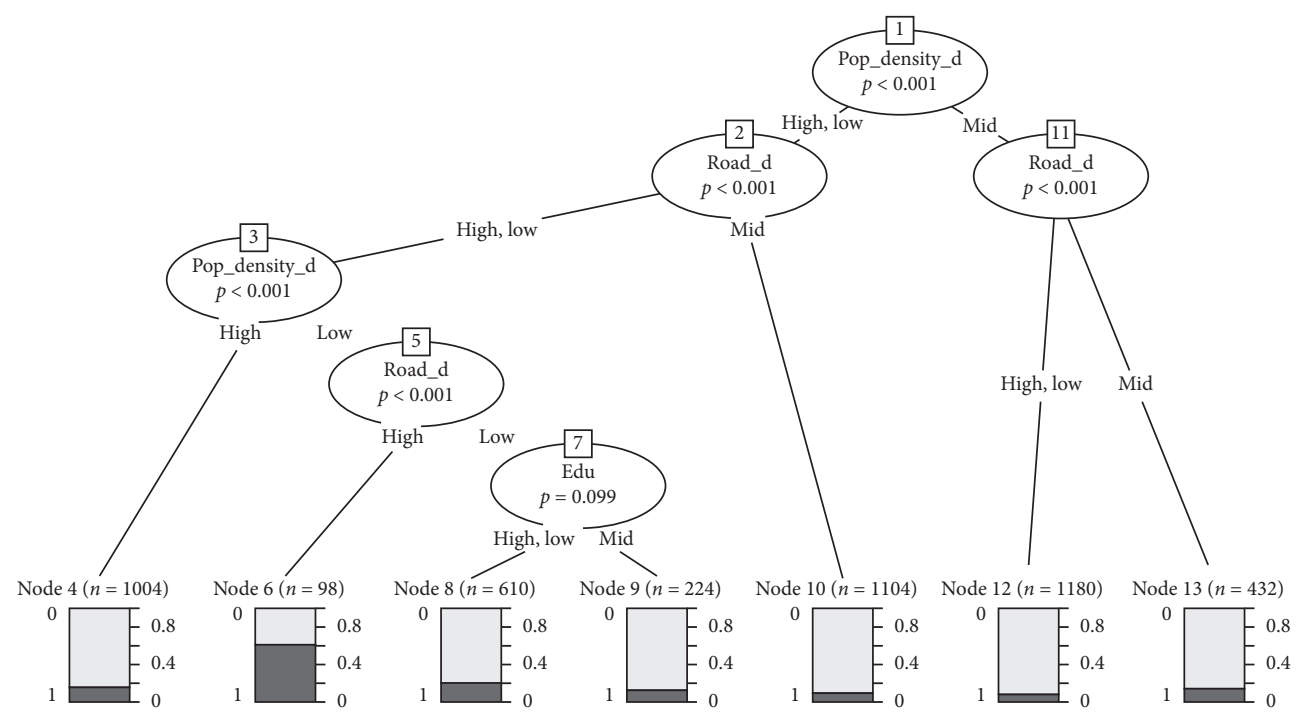

FIGURE 8: Conditional inference tree for all samples. Note: each node of the branch is numbered.

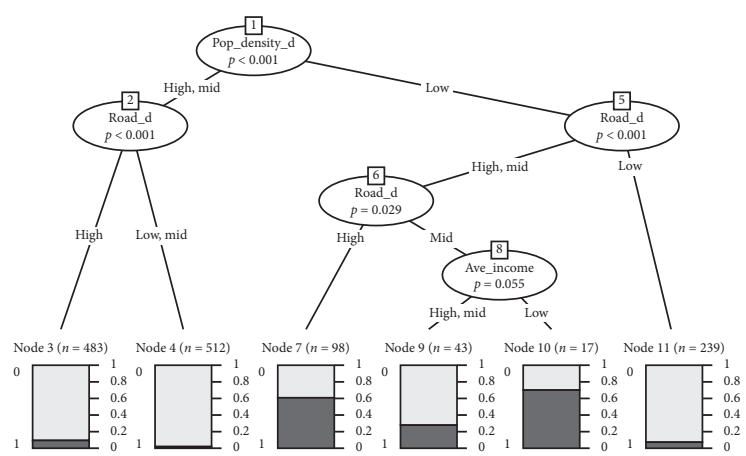

$\mathrm{NE}$
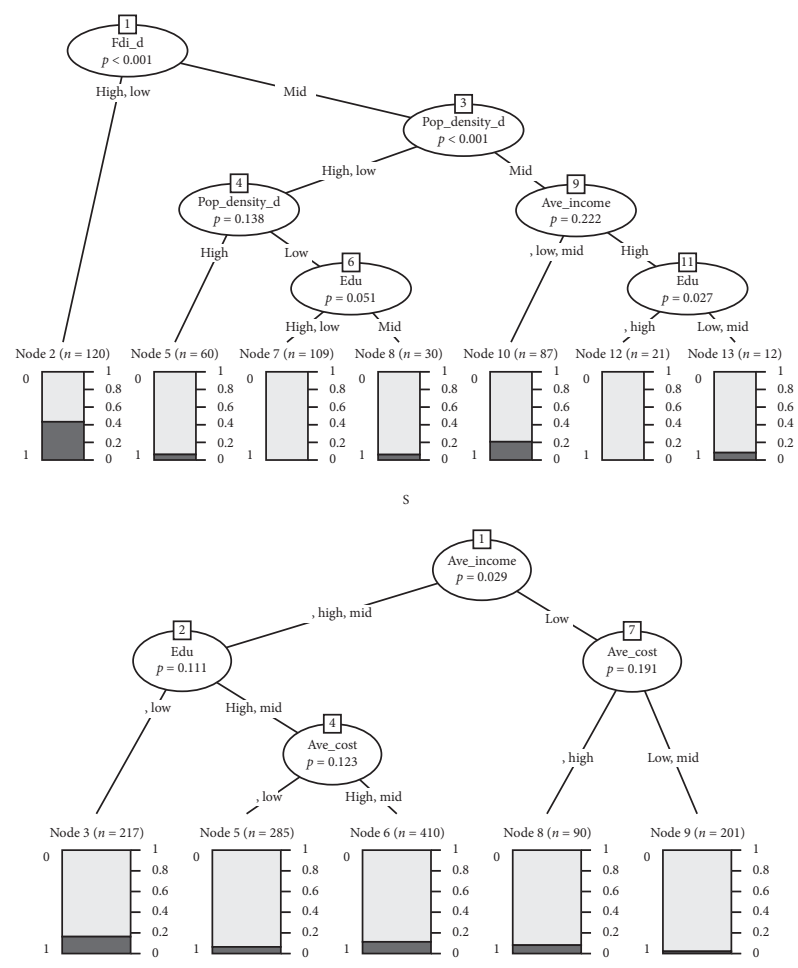

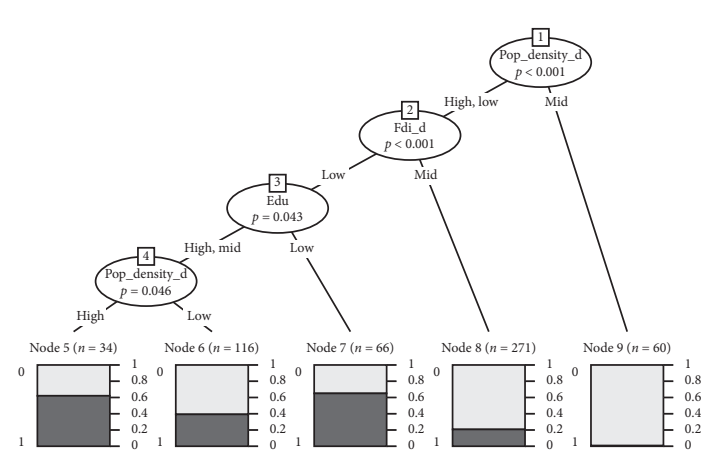

NW
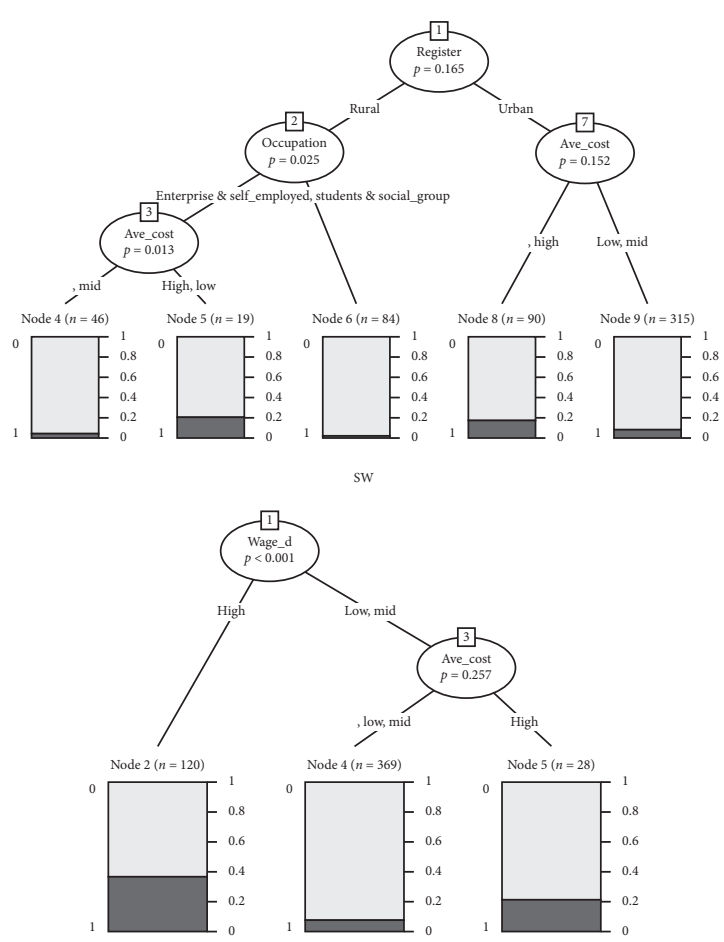

Figure 9: Conditional inference tree of six geographical regions. 


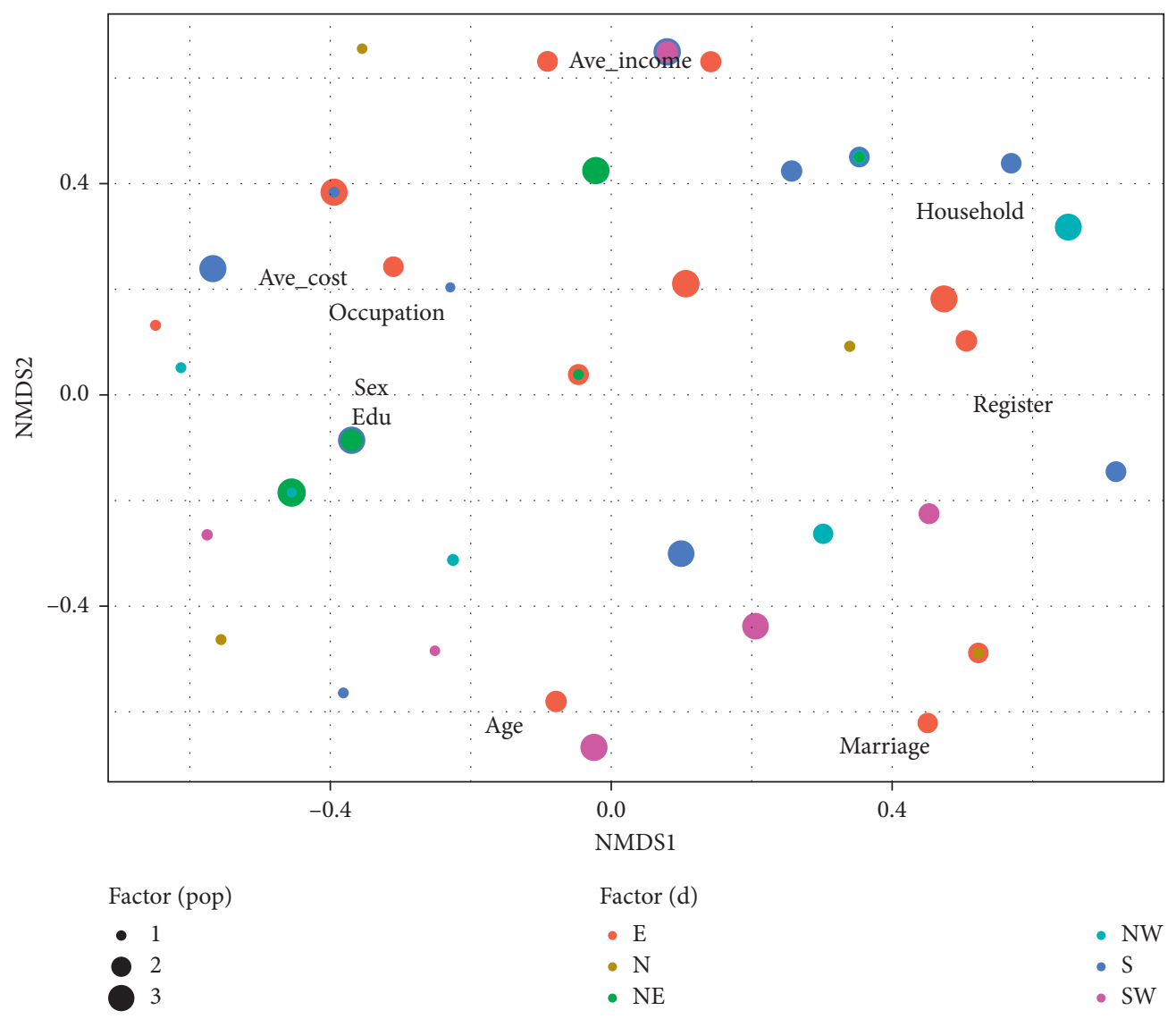

Figure 10: Nonmetric multidimensional scaling (NMDS) analysis of top significant factors. Note. (1) Pop represents the population of the city; the larger the circle, the larger the population. (2) Factor $\mathrm{d}$ represents the six regions. (3) Its coordinate axis is only set to reflect the distance relationship between samples after downscaling.

In addition, from node 7 , the education node divides the sample into two terminals: terminal 8 is "below high school" and "bachelor degree or above"; node 9 is "technical secondary school and higher vocational school" group. It can be seen from the figure that the sample size of node 8 is larger than that of node 9 , indicating that this group of people has a greater probability of making positive evaluation of the environment. For one thing, more educated people may have better knowledge and ability to manage personal health and access to healthcare, higher incomes, better jobs, and stronger social connections and then improve health. Educational attainment may also be associated with differences in occupational exposure, living conditions, or baseline health status [23]. However, lower socioeconomic groups are at increased risk of mortality and morbidity after exposure to environmental pollution. George [19] also found a higher susceptibility to environmental pollution in the least-educated population, as well as higher risk factors that affect health when exposed to air pollution. At the same time, because of the realistic environmental pressure caused by economic, unemployment, and even security problems faced by undereducated people, attention to environmental protection issues is reduced, so it is easier to give better environmental evaluation [24].

There is a general recognition that higher education is often associated with a broader awareness of environmental pollution. Thus, we have to admit that, with the improvement of social education level (especially in developing countries), more and more people will start to notice the change of environmental quality. Therefore, strengthening basic education and environmental awareness education are effective tools to improve the awareness of environmental quality.

3.4. Regional Heterogeneity Analysis. Samples in this study cover 56 cities in China, so whether these driving factors have similar rules in each city (or the region where they are located) is the question to be explored in this section. Consistent with the above method, we first applied the random forest algorithm to the samples of China's six major geographical regions to calculate the main influencing factors of each region (see Figure S1). Figure 9 shows the conditional inference trees of the six regions in China. In general, it can be found that the main factors influencing the subjective and objective evaluation differences are urban factors in east China, north China, and northeast China. The three most important factors are population density, foreign direct investment, and urban road area. In the northwest, southwest, and south, the main factors are individual factors, such as education, household registration, income, and expenditure. In the six districts, the main 
environmental problems faced by each district are basically similar. The economic and cultural environment of its residents is relatively consistent. Here, we can assume that the characteristics of residents of "adjacent cities" have more commonality. We use the nonmetric multidimensional scale (NMDS) to visualize the relationship between cities and predictors as accurately as possible in low-dimensional space.

In addition, we assume that the characteristics of the residents of the "same area" have more commonality. We use the nonmetric multidimensional scaling (NMDS) to visualize the relationship between cities and factors in lowdimensional space more accurately. We should consider nine factors due to the multidimensional nature of our data. Based on that, it is necessary to do NMDS sequencing and multivariate techniques.

It is not difficult to find that there is no centralized distribution of the influencing factors, which is conducive to the observation of urban distribution in Figure 10. Obviously, around each of the main factors, we cannot see a concentration of cities in the same region, and all the cities are scattered in the ordering space. Although the results are contrary to our hypothesis that the consistency of the influencing factors with the regional environment is not obvious, the heterogeneity of the key influencing factors in each city to the environmental assessment indicates that each city has its own relatively unique set of correlations. For example, there are many samples clustered around ave_cost, occupation, edu, and sex, and some samples are clustered around household and ave_income to varying degrees. Thus, the policy formulation of promoting residents' environmental awareness and environmental relevance should be adjusted according to the special situation of each region.

Taking cities in northeast and southern China clustered around educational factors as examples, the CTREE analysis of these two origins also shows that educational factors have a greater impact on them. Therefore, policy makers can focus on analyzing the deeper relationship between educational factors and environmental quality and environmental assessment, so as to guide policy formulation.

\section{Conclusion}

First of all, it should be affirmed that the environmental evaluation of cities is driven by different factors. The empirical results of this paper make us better understand the importance of these factors and how they work together. From a national perspective, the situation of lower population density and better transportation infrastructure in cities can bring about more perceptive environmental optimization. In particular, it should be pointed out that the importance of population density is always important in the analysis of the whole sample. The increase of population density will increase the demand for housing and automobiles, which will lead to the increase in the emission of construction dust, automobile exhaust, and other pollutants. It will affect the environmental quality [22]. Hence, the appropriate increase of urban road investment matching the growth rate of car ownership should pay special attention to the growth of road area, so as to improve the smoothness of urban traffic, reduce the emission of air pollutants, and achieve the balance and all-round development of urban traffic.

On the other hand, from the perspective of cities, we found that educational factors frequently appeared. The results of conditional inference tree also proved the above basic hypothesis: the influence of education on environmental evaluation is not linear. Residents with high and low education levels are more likely to make better environmental assessment choices on the basis of their respective factors. Although the results showed that people with lower education also tended to give higher environmental quality ratings, this "positive feedback" was irrelevant to environmental improvements. Consequently, it is a better choice to strengthen basic education and environmental protection education, enhance residents' awareness of environmental protection, and promote the improvement of environmental quality.

Meanwhile, the consistency of major factors among regions is not obvious and the situation that different cities share the same factors is also not significant. Since there is no significant consistency between the major influencing factors in different regions and cities, we should not ignore the influence of subsidiary factors, although we pay close attention to the analysis of the major factors and these factors with the highest evaluation rate. Consequently, according to the main driving factors, the city can adjust its political focus under the guidance of the unified national environmental policy.

\section{Data Availability}

The data are available from the corresponding author upon request.

\section{Conflicts of Interest}

The authors declare that they have no conflicts of interest.

\section{Acknowledgments}

This work was supported by the Central University Basic Scientific Research Business Expenses Special Funds of China (no. $502000 * 172220192$ ).

\section{Supplementary Materials}

The supplementary file shows the random forest results of the six regions in China representing the ranking of important drivers for each region. (Supplementary Materials)

\section{References}

[1] G. Moser, "Quality of life and sustainability: toward personenvironment congruity," Journal of Environmental Psychology, vol. 29, no. 3, pp. 351-357, 2009.

[2] J. Klemm and Manza, "Social policy responsiveness in developed democracies," Comparative Economic and Social Systems, vol. 3, pp. 53-65, 2011. 
[3] Y. Su and X. Hyatt, "Comparison of environmental quality and public cognition: an observation on self-livelihood index," Reform, vol. 9, pp. 95-104, 2014.

[4] J. Silva, F. D. Keulenaer, and N. Johnstone, Environmental Quality and Life Satisfaction, OECD Publishing, Paris, France, 2012.

[5] J. B. Lansing and R. W. Marans, "Evaluation of neighborhood quality," Journal of the American Institute of Planners, vol. 35, no. 3, pp. 195-199, 1969.

[6] J. D. Porteous, "Design with people," Environment and Behavior, vol. 3, no. 2, pp. 155-178, 1971.

[7] I. Van Kamp, K. Leidelmeijer, G. Marsman et al., "Urban environmental quality and human well-being: towards a conceptual framework and demarcation of concepts; a literature study," Landscape and Urban Planning, vol. 65, no. 1-2, pp. 5-18, 2003.

[8] K. H. Craik and N. R. Feimer, "Environmental assessment," in Handbook of Env. Psych, D. Stokols and I. Altman, Eds., vol. 2, pp. 891-918, Wiley, New York, NY, USA, 1987.

[9] I. Petrosillo, G. Zurlini, M. E. Corlianò, N. Zaccarelli, and M. Dadamo, "Tourist perception of recreational environment and management in a marine protected area," Landscape and Urban Planning, vol. 79, no. 1, pp. 29-37, 2007.

[10] J. I. Nassauer, "Monitoring the success of metropolitan wetland restorations: cultural sustainability and ecological function," Wetlands, vol. 24, no. 4, pp. 756-765, 2004.

[11] L. Pendleton, N. Martin, and D. G. Webster, "Public perceptions of environmental quality: a survey study of beach use and perceptions in Los Angeles county," Marine Pollution Bulletin, vol. 42, no. 11, pp. 1155-1160, 2001.

[12] L. Breiman, "Bagging predictors," Machine Learning, vol. 24, no. 2, pp. 123-140, 1996.

[13] T. M. Lee, E. M. Markowitz, P. D. Howe, C.-Y. Ko, and A. A. Leiserowitz, "Predictors of public climate change awareness and risk perception around the world," Nature Climate Change, vol. 5, no. 11, pp. 1014-1020, 2015.

[14] L. Breiman, Classification and Regression Trees, Routledge, Abingdon-on-Thame, UK, 2017.

[15] J. R. Quinlan, C4. 5: Programs for Machine Learning, Elsevier, Amsterdam, Netherlands, 2014.

[16] H. Strasser and C. Weber, On the Asymptotic Theory of Permutation Statistics, Springer, Berlin, Germany, 1999.

[17] J. B. Kruskal, "Nonmetric multidimensional scaling: a numerical method," Psychometrika, vol. 29, no. 2, pp. 115-129, 1964.

[18] F. W. Young, "Nonmetric multidimensional scaling: recovery of metric information," Psychometrika, vol. 35, no. 4, pp. 455-473, 1970.

[19] M. K. George, "Life satisfaction and air quality in London," Ecological Economics, vol. 68, pp. 1-32, 2008.

[20] H. Kan, S. J. London, G. Chen et al., "Season, sex, age, and education as modifiers of the effects of outdoor air pollution on daily mortality in Shanghai, China: the public health and air pollution in Asia (PAPA) Study," Environmental Health Perspectives, vol. 116, no. 9, pp. 1183-1188, 2008.

[21] M. S. O’Neill, M. L. Bell, N. Ranjit et al., "Air pollution and mortality in Latin America," Epidemiology, vol. 19, no. 6, pp. 810-819, 2008.

[22] Y. Q. Qiu, P. Zhou, and H. C. Sun, "Assessing the effectiveness of city-level electric vehicle policies in China," Energy Policy, vol. 130, pp. 22-31, 2019.

[23] S. Zhou, "How can Chinese people have a higher level of happiness based on the Chinese people's livelihood index," vol. 6, pp. 8-21, 2015, (in Chinese).
[24] Y. Huang, "Urbanization _ environmental pollution and residents subjective well-being _ empirical evidence from China," IOP Conference Series: Earth and Environmental Science, vol. 12, pp. 82-93, 2013, (in Chinese). 